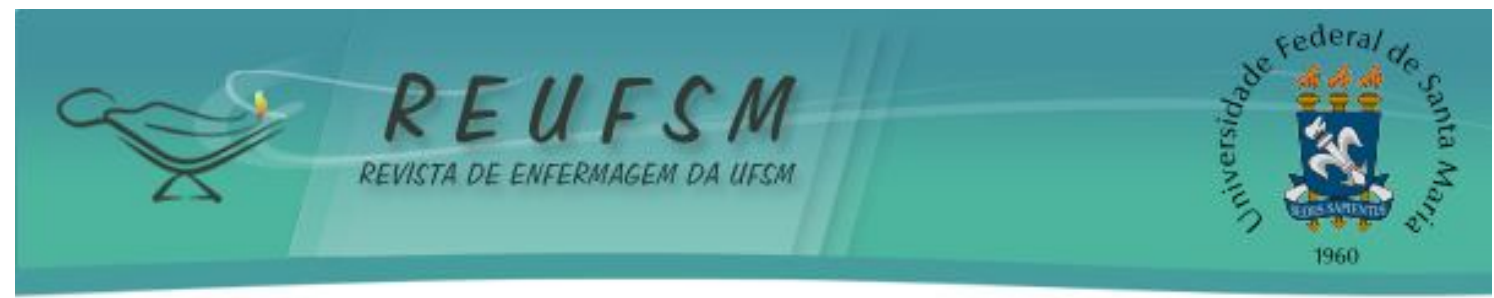

RELATO DE EXPERIÊNCIA

\title{
CONTRIBUIÇÕES DE UM NÚCLEO DE ESTUDOS NA CONSOLIDAÇÃO DE POLÍTICAS PÚBLICAS PARA AS MULHERES
}

\author{
CONT RIBUTIONS OF A CORE OF ST UDIES IN THE CONSOLIDATION OF PUBLIC \\ POLICIES FOR WOMEN
}

\section{CONT RIBUCIONES DE UN NUCLEO DE EST UDIOS EN LA CONSOLIDACIÓN DE LAS POLITICAS PUBLICAS PARA LAS MUJERES}

\author{
Maria Celeste Landerdahl ${ }^{1}$ \\ Letícia Becker Vieira ${ }^{2}$ \\ Lizandra Flores Pimenta ${ }^{3}$ \\ Rosana Vargas Fraga ${ }^{4}$ \\ Karine J acques Hentges ${ }^{5}$ \\ Mariana Resener de Morais ${ }^{6}$
}

RESUMO: Objetivo: relatar a experiência de origem e desenvolvimento de um núcleo de estudos em saúde da mulher, cujas ações ultrapassam as questões biológicas da saúde feminina. Método: trata-se de um relato de experiência a partir das vivências no desenvolvimento de atividades de extensão e pesquisa do Núcleo de Estudos sobre Mulheres, Gênero e Políticas Públicas - NEMGeP, do Departamento de Enfermagem da Universidade Federal de Santa Maria - UFSM. Resultados: destacam-se ações de extensão relevantes e pesquisas nas temáticas gênero, violência contra as mulheres e mulheres na construção civil. Conclusão: Destaca-se a necessidade de as instituições formadoras e grupos/ núcleos de estudos e pesquisas se alinharem às premissas das políticas públicas, como forma de preparar profissionais atentos e sensíveis à redução de desigualdades, respeito à diversidade cultural, inclusão social e configurando-se como possíveis mediadores de processos de autonomia das mulheres.

Descritores: Enfermagem; Saúde da mulher; Políticas públicas; Cidadania; Gênero.

ABSTRACT: Objective: To report the experience of the origin and development of a core of women's health studies, relating references to discussions and reflections on gender and citizenship because of the urgency of consolidating these approaches in caring for the female audience. Method: from the experiences in developing research and extension activities of the Core of Studies on Women, Gender and Public Policy, Department of Nursing, Federal University of Santa Maria. Results: stand out extent relevant actions and studies have been conducted on gender issues, violence against women and women in construction. Conclusion: The study highlights the need of the educational institutions

\footnotetext{
${ }^{1}$ Enfa. Dda. em Enfermagem. Docente do Departamento de Enfermagem da Universidade Federal de Santa Maria. E-mail- mclanderdahl @gmail.com

${ }^{2}$ Enfạ. Mda. do Programa de Pós-Graduação do Curso de Enfermagem da Universidade Federal de Santa Maria. E-mail- letsbv@yahoo.com.br

${ }^{3}$ Enfa Mda. da Pós Graduação do Curso de Enfermagem da Universidade Federal de Santa Maria. Email- liflopi@bol.com.br

${ }^{4}$ Assistente Social Mda. em Ciências Sociais da Universidade Federal de Santa Maria. E-mailrosannavargas12@hotmail.com

${ }^{5}$ Pedagoga. Acadêmica do Curso de Educação Especial da Universidade Federal de Santa Maria. Email- karinej hentges@gmail.com

${ }^{6}$ Acadêmica do Curso de Psicologia da Universidade Federal de Santa Maria. E-mailmari_rm_@hotmail.com
} 


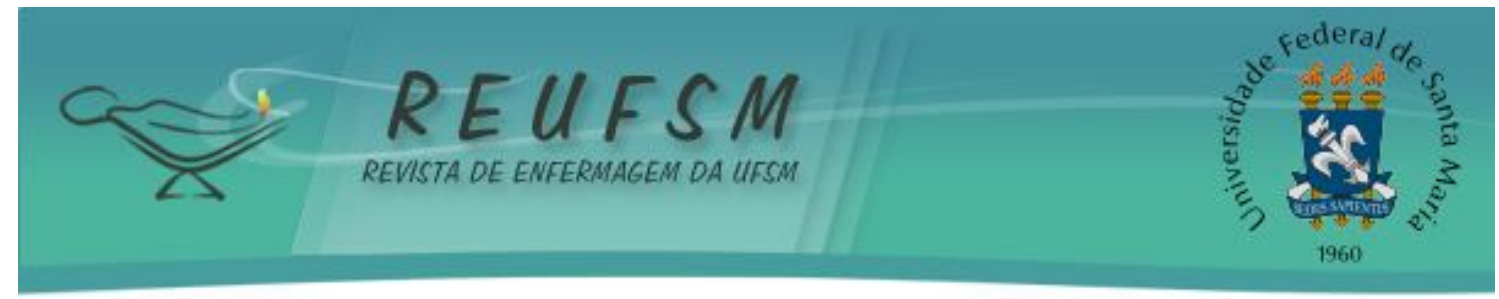

and groups of studies and research to align themselves to the assumptions of public policies as a way to prepare professionals attentive and sensitive to the inequalities reducing, respect for cultural diversity, social inclusion and configuring as possible mediators of processes of empowerment of women.

Descriptors: Nursing; Women's health; Public policies; Citizenship; Gender.

RESUMEN: Objetivo: Presentar la experiencia del origen y desarrollo de un núcleo de estudios de salud de la mujer cuyas acciones van más allá de las cuestiones biológicas de la salud femenina. Método: relato de experiencias a partir de vivencias en el desarrollo de actividades de investigación y de extensión del Grupo de Estudios sobre la Mujer, Género y Políticas Públicas, Departamento de Enfermería de la Universidade Federal de Santa Maria - UFSM. Resultados: se destacan acciones pertinentes e investigaciones sobre temas de género, violencia contra la mujer y mujeres en la construcción civil. Conclusión: el estudio destaca la necesidad de que las instituciones educativas y los grupos de estudios e investigación se alineen con los supuestos de la política pública como forma de preparar a profesionales atentos y sensibles a la disminución de las desigualdades, al respeto a la diversidad cultural, a la inclusión social, configurándose como posibles mediadores de los procesos de autonomía de la mujer.

Descriptores: Enfermería; Salud de la mujer; Políticas públicas; Ciudadanía; Género.

\section{INTRODUÇÃO}

Preocupações com o ecossistema e com o bem-estar dos indivíduos têm desencadeado discussões, cujo objetivo principal é a defesa da vida, o que implica, dentre outros aspectos, na garantia de direitos humanos. A evidência disso se revela por meio de inúmeros eventos internacionais realizados a partir da década de 40 do século passado, os quais contém enunciados, definições e recomendações que tentam assegurar direitos humanos mínimos para todos os habitantes do planeta. ${ }^{1}$

No Brasil, em especial nos últimos 35 anos, tais pressupostos, dentre outros, têm subsidiado o processo de redemocratização do país, repercutindo em várias áreas. Com a anistia política de 1979 houve um impulso significativo às discussões que movimentos sociais já vinham abordando, em especial os relacionados ao feminismo e à ecologia. ${ }^{2}$ No que se refere à saúde, a Reforma Sanitária vem se instituindo, por meio de uma política de saúde fundada em pilares que priorizam a promoção da saúde.

Nesse grande cenário, a política de atenção à saúde feminina vem recomendando uma abordagem mais ampla às mulheres brasileiras. Suas premissas evidenciam a urgência em olhar a mulher para além de sua maternidade. Nessa corrente, além dos aspectos biológicos, a mulher deve ser percebida em sua dimensão social, econômica, histórica, política e cultural, uma vez que é na interação desses aspectos que resulta o perfil de saúde e doença dos indivíduos. ${ }^{3}$

Inserida nesse contexto, encontra-se a questão de gênero, entendida como a construção cultural do ser feminino e masculino, trazendo em sua essência a marca do poder favorecendo relações desiguais entre homens e mulheres. ${ }^{4}$ Aponta-se, assim, que em função da organização social das relações de gênero, as mulheres estão mais vulneráveis ao sofrimento, adoecimento e morte. Com isso, fica evidente que as questões de gênero devem ser consideradas, também, como determinantes da saúde das mulheres na elaboração de políticas públicas. Com esse enfoque amplia-se a abordagem à mulher, pois envolve seu contexto de vida no âmbito dos direitos humanos. 


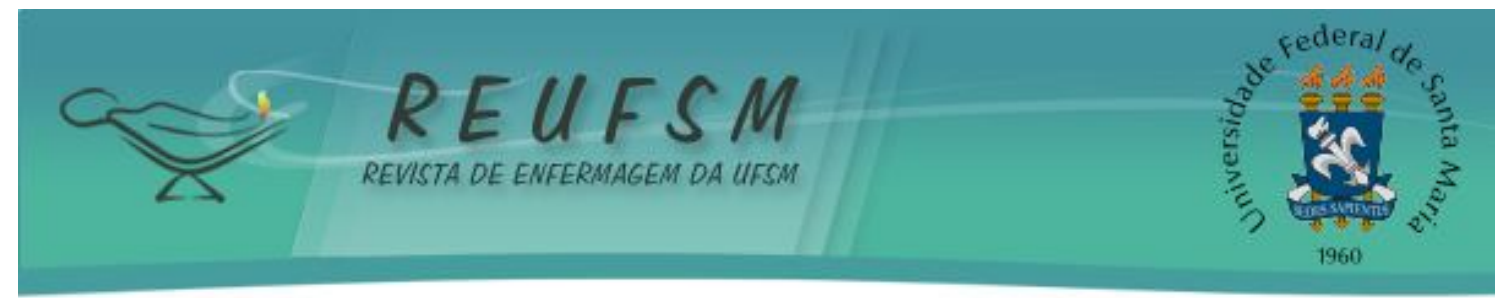

Essa realidade representa um desafio para a formação de profissionais da área da saúde, pois significa superar uma cultura apoiada em preconceitos e discriminações que as mulheres vêm sofrendo ao longo da história. Implica em perceber outros condicionantes presentes para o bem-estar das mulheres e, a partir daí, realizar intervenções condizentes com sua realidade. A enfermagem, como prática que se envolve com questões políticas e sociais, deve se engajar nesse movimento como forma de ir ao encontro das demandas das mulheres, consolidando o conceito ampliado de saúde.

Amparado em tais reflexões, o presente artigo tem como objetivo relatar a experiência de origem e desenvolvimento de um núcleo de estudos em saúde da mulher, cujas ações ultrapassam as questões biológicas da saúde feminina.

\section{MÉTODO}

Trata-se de um relato de experiência a partir das vivências no desenvolvimento de atividades de extensão e pesquisa do Núcleo de Estudos sobre Mulheres, Gênero e Políticas Públicas - NEMGeP, do Departamento de Enfermagem da Universidade Federal de Santa Maria - UFSM.

\section{Alguns referenciais balizadores para uma abordagem ampliada da saúde das mulheres}

Sem desconsiderar referenciais ancorados na dimensão biológica, pretende-se alinhar nesse espaço, questões que dizem respeito ao contexto teórico-filosófico da política de atenção à saúde das mulheres. Para tanto, serão abordados alguns elementos históricos fundamentais, uma vez que explicam o enfoque dado pela atual política pública de atenção à saúde no Brasil e, em especial, a saúde das mulheres.

Um deles diz respeito à garantia de direitos humanos (DH). A ideia de $\mathrm{DH}$ como entendido atualmente é relativamente nova, tendo surgido pela primeira vez na Revolução Francesa, cujos ideais - liberdade, igualdade e fraternidade - foram divulgados e influenciaram leis de vários países. ${ }^{5}$

Nessa direção, já no século XX, após a Segunda Guerra Mundial, a Organização das Nações Unidas aprovou a Declaração Universal dos Direitos Humanos, primeiro documento internacional elaborado para defender os direitos da humanidade. ${ }^{5}$ Em seu Artigo 1 o diz que "todas as pessoas nascem livres e iguais em dignidade e direitos". ${ }^{6}$

Esse enunciado continua simbolizando intenções que passaram, a gerar transformações na sociedade às custas de uma maior consciência mundial na busca pela integração entre os povos, tendo a vida e a paz como fim. Na área da saúde, principalmente nos países de primeiro mundo "[...] os sistemas de saúde começam, na metade dos anos 70, a serem fortemente questionados, tendo como pano de fundo novas concepções do processo saúde-enfermidade-cuidado". 7:21 Movimentos de vários segmentos sociais intensificaram suas indagações sobre a ineficiência do enfoque à saúde centrado no pensamento biomédico, com ênfase na cura de doenças. ${ }^{8}$ As discussões priorizavam a promoção da saúde como uma das formas de superar a questão da fragmentação da atenção à saúde.

Nesse cenário, o Informe Lalonde, de 1974 foi o primeiro documento oficial de promoção da saúde, o qual defendia saúde como resultado de um conjunto de fatores agrupáveis em quatro categorias, que não se limitavam somente ao aspecto biológico; evidenciando que outros elementos, como estilo de vida e ambiente deveriam ser considerados naquilo que se inaugurava como promoção da saúde. ${ }^{7}$ 


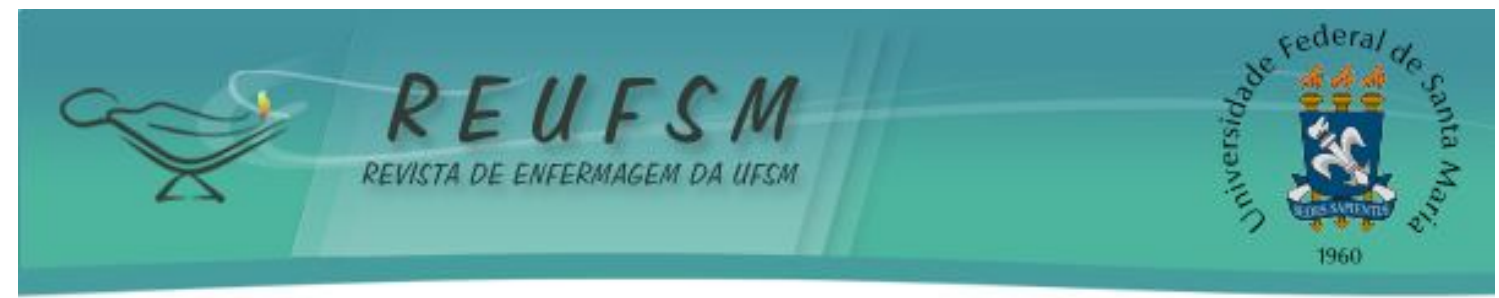

As Cartas de Promoção da Saúde, resultantes de eventos internacionais posteriores, vêm estimulando agendas governamentais a fim de que as políticas públicas sejam favoráveis à saúde e à vida, com o fortalecimento do protagonismo cidadão. ${ }^{9} \mathrm{Com}$ isso, busca-se construir um conceito ampliado de saúde, no qual as dimensões sociais, políticas, culturais, dentre outras, são determinantes no processo saúde-doença.

Em consonância com esse movimento, no Brasil, a Conferência de Alma Ata, realizada na URSS em 1978, impulsionou a Reforma Sanitária, sendo fonte inspiradora do atual Sistema Único de Saúde (SUS), o qual tem suas bases assentadas em uma concepção de saúde como direito de cidadania, sendo resultante das condições de vida da população. ${ }^{10}$

No bojo da Reforma Sanitária que se pensava, era necessário abordar, de forma mais pontual, a atenção à saúde das mulheres. Assim, no final de 1970 e início de 1980, diversas formas de organização política somaram ao debate os direitos reprodutivos, que, até então, não eram considerados como do âmbito da saúde. ${ }^{2}$

0 protagonismo dessa iniciativa ficou a cargo de feministas, que percebiam a necessidade de superar a visão que reduzia a mulher ao ciclo gravídico-puerperal vigente nos programas e ações de saúde. Era preciso considerar outros elementos na vida das mulheres, dentre esses a discriminação ao segmento feminino. Tomava corpo, na esteira da saúde, a busca pela defesa dos direitos humanos das mulheres.

Nesse sentido, a Convenção sobre a Eliminação de Todas as Formas de Discriminação contra a Mulher, adotado pela Assembléia Geral das Nações Unidas em 1979, representou importante marco na defesa dos direitos femininos, evidenciando a pressão do Movimento Feminista, em nível mundial. Tal documento tem como princípios a igualdade de direitos, o respeito à dignidade humana e a participação das mulheres na vida política, social, econômica e cultural de seu país, nas mesmas condições que o homem. Apregoa, ainda, que para assegurar tais direitos, os governos devem tomar medidas concretas para promoção da igualdade entre homens e mulheres. ${ }^{5}$

Com tantas manifestações, foi possível questionar o Programa de Saúde MaternoInfantil (PSMI), vigorante na época, o qual não considerava as necessidades e especificidades das mulheres no seu contexto de vida, atendo-se somente ao período gravídico-puerperal. Situação que encaminhou, ao longo da década de 80 e início de 90 , para as primeiras experiências na elaboração de políticas públicas com perspectiva de gênero. ${ }^{2}$ Com essa ideia ainda incipiente nasceu, em 1984, o Programa de Atenção Integral à Saúde da Mulher (PAISM), o qual recomendava atenção integral ao segmento feminino desde a adolescência até a terceira idade, despertando, também, para a atenção à saúde da mulher como uma questão de direito.

Há que se referir, nessa traj etória, a promulgação da Constituição Brasileira, em 1988, a qual assegura, no art. 5ำ, capítulo I, que "todos são iguais perante a lei [...]" e, no inciso I, que "homens e mulheres são iguais em direitos e obrigações [... ]". "2:5 Reconhece também, no art.196 na Seção da Saúde, que "a saúde é um direito de todos e dever do Estado". ${ }^{2: 141}$ Percebe-se que o contexto continuava a conspirar a favor dos direitos humanos, incluídos aí os das mulheres.

Outros eventos constituem marcos na busca por melhores condições de saúde da população feminina na perspectiva dos direitos humanos. Dentre esses, a Conferência Internacional de População e Desenvolvimento, no Cairo, em 1994, abordou a saúde reprodutiva de forma abrangente, estabelecendo prioridade nos indicadores de saúde relativos ao bem-estar geral da população feminina. Reconheceu, também, que a mulher tem direito de ter autoridade sobre seu corpo, podendo tomar decisões sobre sua vida sexual e reprodutiva; afirma também, que o Estado tem o dever de fornecer meios para que a autonomia seja exercida em sua plenitude. ${ }^{2}$ Nessa esteira, em 1996 o Brasil sancionou a Lei 9263 , assegurando o planejamento familiar como direito de cidadania. ${ }^{12}$ 


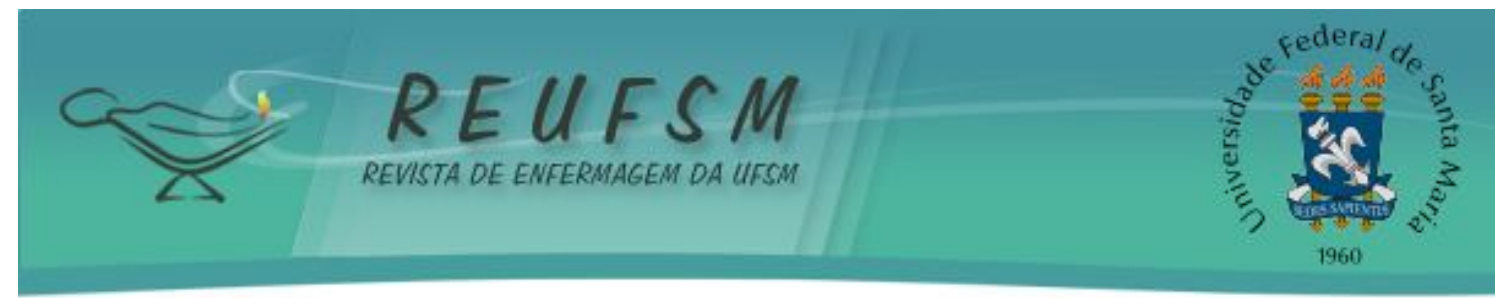

Concomitante a isso, desde 1980, ganha visibilidade a violência de gênero, exigindo avanços, dentre os quais a criação de delegacias para o atendimento de vítimas de violência de gênero. Nessa perspectiva "[...] os direitos humanos das mulheres só serão alcançadas quando enfrentarmos com determinação a discriminação e a violência que atingem as mulheres em nossa sociedade" . 5:9

A violência contra a mulher vem sendo considerada como um tema de saúde pública, tanto por associações profissionais, como pelo Movimento Feminista, serviços de saúde e organismos internacionais. ${ }^{13}$ Isso porque o fenômeno saiu da esfera do privado, uma vez que está associada a um maior risco para diversos agravos à saúde física e mental, bem como ao uso mais frequente dos serviços de saúde. ${ }^{14}$ Atinge, ainda, parcela importante da população, configurando-se num problema exacerbado e multifacetado. ${ }^{15}$

0 amadurecimento dessa temática conduziu, em 1994, à criação da Convenção Interamericana para Prevenir, Punir e Erradicar a Violência contra a Mulher - Convenção de Belém do Pará, pela Organização dos Estados Americanos, constituindo importante instrumento legal internacional de defesa dos direitos das mulheres. ${ }^{5}$

Em consonância com essa caminhada, o Ministério da Saúde elaborou, em 2004, a Política Nacional de Atenção Integral à Saúde da Mulher. Esse documento "incorpora, na perspectiva de gênero, a integralidade e a promoção da saúde, buscando consolidar avanços no campo dos direitos sexuais e reprodutivos". "4:5 Enfatiza, ainda, o combate à violência doméstica e sexual, bem como a importância do empoderamento das usuárias do SUS como instrumento de autonomia e participação no controle social. ${ }^{4}$

Essa traj etória evidencia a tentativa do Brasil em se alinhar às recomendações de conferências e convenções internacionais que visam garantir os direitos humanos das mulheres, seja no âmbito de políticas públicas ou no âmbito legal. Nesse caso, cita-se a Lei no 11.340 , que, dentre outras conquistas, tipifica os crimes de violência contra a mulher, bem como os procedimentos judiciais, além de classificar esse crime como uma das formas de violação aos direitos humanos das mulheres. ${ }^{16}$

As conquistas das brasileiras não se esgotam aqui. É importante referir a la Conferência Nacional de Políticas para as Mulheres (CNPM), realizada em 2004 e a IIa em 2007, as quais deram origem ao Plano Nacional de Políticas Públicas para as Mulheres - PNPM. Este plano agrega dez eixos de ações estratégicas e, tem como premissa básica garantir mais cidadania para mais brasileiras por meio da eliminação da discriminação contra as mulheres, colocando para isso, as questões de gênero e raça transversais às políticas públicas. ${ }^{17}$

Percebe-se no conjunto dos eixos, a preocupação com a busca por igualdade social, garantia de direitos e empoderamento feminino, como estratégias para superação de desigualdades de gênero. Nas palavras da Ministra da Secretaria de Política para as Mulheres da Presidência da República Nilcéa Freire, "o PNPM é a expressão inequívoca do compromisso do governo brasileiro com a igualdade e a justiça social para todos e todas" ${ }^{17: 18}$

\section{Núcleo de estudos sobre Mulheres, Gênero e Políticas Públicas: instrumento de intervenção na vida das mulheres}

A academia tem o papel de produzir e disseminar conhecimentos considerando os avanços nas políticas públicas no Brasil, em especial as dirigidas às mulheres, podendo fazê-lo na medida em que cria espaços para discussão e intervenção social.

Nessa perspectiva, o Núcleo de Estudos sobre Mulheres, Gênero e Políticas Públicas - NEMGeP, do Departamento de Enfermagem da Universidade Federal de Santa Maria- RS, vem construindo sua trajetória na abordagem à saúde da mulher para além da dimensão biológica, na medida em que considera as questões de gênero e as Políticas Públicas para as mulheres como referenciais fundamentais no direcionamento da atenção 


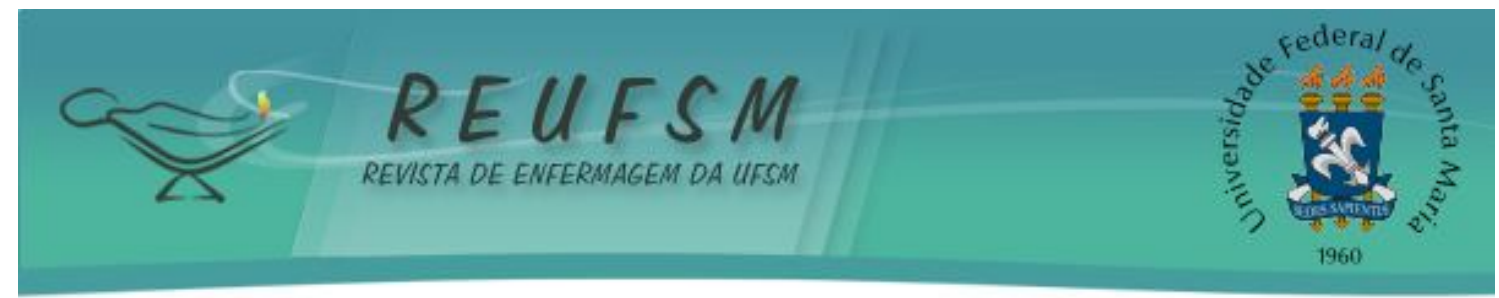

ao público feminino. Cabe salientar que é um núcleo de estudos recente, tendo seu registro no Diretório dos Grupos de Pesquisa no Brasil/CNPq datado de maio de 2009, embora já mantivesse há mais de 10 anos, atividades independentes ou junto a outros grupos de pesquisas do Departamento de Enfermagem/ UFSM.

Este núcleo integra profissionais e acadêmicos de várias áreas do conhecimento, dentre os quais acadêmicos de enfermagem, psicologia, comunicação social e pedagogia, bem como enfermeiras da Secretaria de Município da Saúde e do Hospital Universitário de Santa Maria, docentes do Departamento de Enfermagem e assistentes sociais. A caminhada vem sendo trilhada por meio de iniciativas que possibilitem a garantia dos direitos humanos das mulheres, tendo como foco principal a superação de desigualdades de gênero.

Para tanto, o Núcleo trabalha de forma sistematizada, com reuniões semanais de grande grupo, quando são pactuados cronogramas dos estudos, apresentação de proj etos e relatórios de pesquisas. Da mesma forma, ocorrem encontros diários com estagiárias, como forma de fazer encaminhamentos mais específicos aos proj etos em andamento.

Dentre as iniciativas de intervenção na vida das mulheres, dois projetos, os quais têm implicação direta com políticas públicas atuais, estão sendo implementados. Um deles diz respeito a um Programa de Extensão Universitária, em parceria com o Ministério da Educação - PROEXT, intitulado Mulheres Conquistando Cidadania, ${ }^{18}$ cujo objetivo consiste em "contribuir para a efetivação do Plano Nacional de Políticas Públicas para as Mulheres", situando seu fio condutor no eixo de ação "autonomia econômica e igualdade no mundo do trabalho, com inclusão social" do PNPM.

Dentre as ações propostas no referido programa destacam-se: três edições de cursos profissionalizantes para mulheres na área da construção civil; um espaço de discussões sobre políticas públicas para as mulheres no município; e aglutinação das ações por meio de publicações conjuntas entre os integrantes do NEMGeP. Com 11 meses de duração, o programa deve finalizar em março de 2011.

Os cursos profissionalizantes estão sendo ministrados em dois eixos: o eixo técnico e o eixo saúde/ cidadania. O eixo técnico está sendo desenvolvido pelo Serviço Nacional da Indústria - SENAI em duas opções: assentamento de placas de cerâmicas e pintura predial interna e externa, com carga horária de 70 horas. Já o segundo eixo - saúde/ cidadania, com 30 horas, está sendo implementado pelo NEMGeP, por meio de oficinas que abordam diversos temas, que contribuam para o fortalecimento das mulheres como cidadãs e futuras trabalhadoras de canteiros de obras, âmbito este tradicionalmente masculino. Esse eixo utiliza como metodologia o diálogo e a perspectiva problematizadora, a qual entende o ser humano como agente transformador de sua realidade social, uma vez que, ao desenvolver suas capacidades intelectuais, emocionais e motoras, tem condições de transformar o contexto em que vive. ${ }^{19}$ Os dois eixos estão sendo desenvolvidos concomitantemente, permitindo problematizar o cotidiano de vida das mulheres e as aulas práticas, possibilitando a troca entre o saber popular e 0 acadêmico. Para tanto, os conteúdos do eixo saúde/ cidadania são implementados por meio de dinâmicas de grupo e rodas de conversa com o intuito de envolver as mulheres como suj eitos nas discussões.

Outra ação do programa diz respeito a realização de discussões com instituições de ensino, esfera municipal de governo e sociedade civil organizada, com objetivo de avaliar a rede que presta atendimento às mulheres, bem como, sensibilizar para possibilidade de elaboração de um Plano Municipal de Políticas Públicas para as Mulheres no município. Essa atividade já vem se ef etivando por meio de eventos em que o NEMGeP tem participado em parceria com a Secretaria de Município de Assistência Social, Cidadania e Direitos Humanos e outras instituições do município de Santa Maria, 


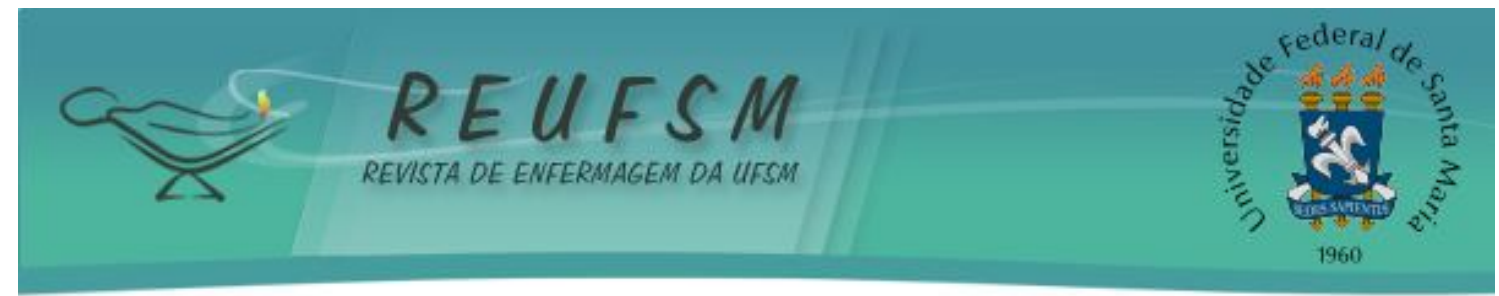

almejando, assim a superação de desigualdades entre homens e mulheres como tema transversal.

Uma segunda iniciativa do NEMGeP, no âmbito de políticas públicas para as mulheres, refere-se ao desenvolvimento de um curso de aperfeiçoamento à distância em "Gestão de Políticas Públicas em Gênero e Raça", ${ }^{20}$ em parceria com o Ministério da Educação - Secretaria de Educação Continuada, Alfabetização e Diversidade e com a Secretaria de Políticas para Mulheres, por meio da Universidade Aberta do Brasil. o Curso tem carga horária de 300 horas e será oferecida para 6 municípios do Rio Grande do Sul, com um total de 270 vagas. Tem como objetivo formar profissionais aptos a atuar no processo de elaboração, aplicação, monitoramento e avaliação de projetos e ações de forma a assegurar a transversalidade de gênero e raça nas políticas públicas. Seu público alvo consiste em servidores dos três níveis da administração pública, integrantes de Conselhos de Direitos das Mulheres, de Fóruns Intergovernamentais de Promoção da Igualdade Racial, de Conselhos de Educação e dirigentes de organismos nãogovernamentais ligados ao tema gênero e igualdade étnico-racial, bem como gestores/ as das áreas de educação, saúde, trabalho, segurança e planejamento.

No que se refere às atividades de pesquisa, o Núcleo tem desenvolvido investigações nas temáticas gênero, violência contra as mulheres, empoderamento feminino; envolvendo alunos/ as de cursos de graduação e pós-graduação. Com isso, é possível perceber que tais temáticas começam a ter visibilidade no espaço acadêmico onde o Núcleo está inserido.

\section{CONSIDERAÇÕES FINAIS}

A implementação de diretrizes políticas na perspectiva da garantia dos direitos humanos e da superação de desigualdades de gênero no que se refere à saúde feminina, têm possibilitado aos integrantes do NEMGeP um olhar ampliado a respeito dos condicionantes da vida e saúde das mulheres. Com isso, fica evidente a urgência de a enfermagem se alinhar à pressupostos políticos como forma de superar a visão biologicista do cuidado.

Da mesma forma, cabe às instituições formadoras considerarem as recomendações políticas oficiais como subsídios para o preparo de profissionais atentos e sensíveis à redução de desigualdades, respeito à diversidade cultural, inclusão social e configurandose como possíveis mediadores de processos de autonomia econômica e empoderamento de mulheres.

Aponta-se, assim, a urgência do enfoque de direitos humanos e gênero na construção e conquista da cidadania, temáticas intimamente ligadas às políticas públicas de atenção à saúde feminina. Ressalta-se que tal perspectiva vem sendo um importante instrumento de empoderamento no alcance da valorização, emancipação e autonomia das mulheres; condições essas que, somadas a outras tantas, contribui na qualidade de vida e saúde das mulheres.

\section{REFERÊNCIAS}

1. Casique LC, Furegato ARF. Violência contra mulheres: reflexões teóricas. Rev latino-am enferm. 2006; 14(6):950-6.

2. Pitanguy J. O movimento nacional e internacional de saúde e direitos reprodutivos. In: Giffin K, Costa SH. Questões da Saúde Reprodutiva. Rio de Janeiro: Editora Fiocruz; 1999. p.19-38. 


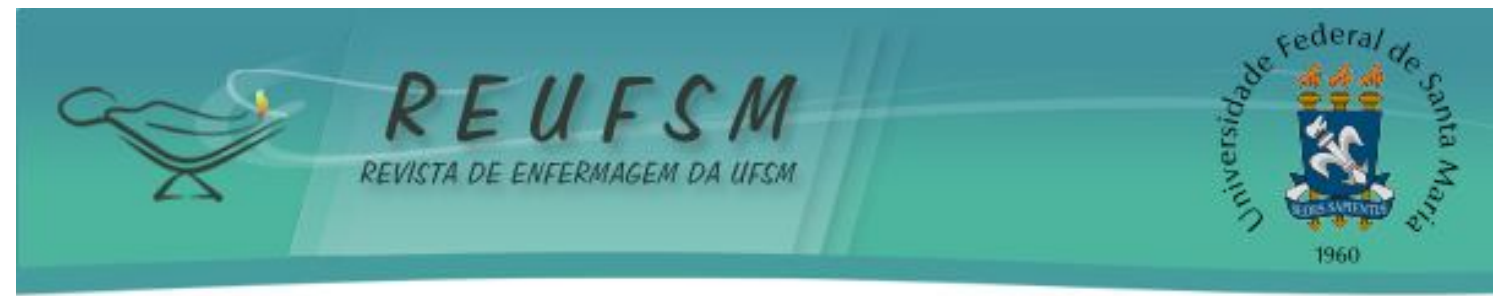

3. Cabral FB, Ressel LB, Landerdahl MC. Consulta de Enfermagem: estratégia de abordagem à gestante na perspectiva de gênero. Esc Anna Nery. 2005; 9(3): 459-65.

4. Ministério da Saúde (BR). Secretaria de Atenção à Saúde. Política Nacional de Atenção Integral à Saúde da Mulher - princípios e diretrizes. Brasília: Ministério da Saúde; 2004.

5. Libardoni A. Direitos humanos das mulheres: em outras palavras - Subsídios para capacitação legal de mulheres e organizações. Brasília: Agende; 2002.

6. Organização das Nações Unidas. Declaração Universal dos Direitos Humanos [Internet]. 1948 [acesso em 2010 ago 16]. Disponível em: http://www.onubrasil. org. br/ documentos_direitoshumanos. php.

7. Buss PM. Uma introdução ao conceito de promoção da saúde. In: Czeresnia D, Freitas CM. Promoção da Saúde: conceitos, reflexões, conceitos. Rio de J aneiro: Editora Fiocruz; 2005.

8. Capra F. O Ponto de Mutação. São Paulo: Cultrix; 1982.

9. Ministério da Saúde (BR). Secretaria de Vigilância em Saúde. Política Nacional de Promoção da Saúde. Secretaria de Atenção à Saúde. Série Pactos pela Saúde, vol 7. Brasília: Ministério da Saúde; 2006.

10. Brasil. Lei $\mathrm{n} \cong .8080$, de 19 de setembro de 1990. Dispõe sobre as condições para a promoção, proteção e recuperação da saúde, a organização e o funcionamento dos serviços correspondentes e dá outras providências. Diário Oficial da União. 20 set.1990. Seção I.p. 18. 055.

11. Brasil. Constituição da República Federativa do Brasil. Texto constitucional de 5 de outubro de 1988. 2ª ed. Brasília: Imprensa Nacional; 1997.

12. Brasil. Lei No 9.263, de 12 de Janeiro de 1996. Regula o § 70 do art. 226 da Constituição Federal, que trata do planejamento familiar, estabelece penalidades e dá outras providências. Diário Oficial da União. 15 jan. 1996, Seção I, p. 561.

13. Secretaria de Atenção à Saúde (BR). Atenção integral para mulheres e adolescentes em situação de violência doméstica e sexual: matriz pedagógica para formação de redes. Brasília: Ministério da Saúde; 2006.

14. Schraiber LB, D'Oliveira AFPL. O que devem saber os profissionais de saúde para promover os direitos e a saúde das mulheres em situação de Violência Doméstica. São Paulo: USP; 1999.

15. Silva GF, Silva MDB, Silva LR, Santos IMM. Violence against woman from the perspective of pregnants women. Rev Enf UFPE On Line [periódico na Internet]. 2009 jul-set [acesso em 2010 mar 09]; (3):33-42. Disponível em: http:/ / www. ufpe. br/ revistaenfermagem/ index. php/ revista/ article/ viewFile/ 153

16. Brasil. Lei №. 11.340 de 07 de agosto de 2006. Cria mecanismos para coibir a violência doméstica e familiar contra a mulher, nos termos do § 8o do art. 226 da Constituição Federal, da Convenção sobre a Eliminação de Todas as Formas de Discriminação contra as Mulheres e da Convenção para Prevenir, Punir e Erradicar a Violência contra a Mulher [...] altera o Código de Processo Penal, o Código Penal e a Lei de Execução Penal; e dá outras providências. DOU. 08 ago.2006. Seção I, p.1.

17. Secretaria Especial de Políticas para as Mulheres (BR). II Plano Nacional de Políticas para as Mulheres. Brasília (DF): Secretaria Especial de Políticas para as Mulheres; 2008. 


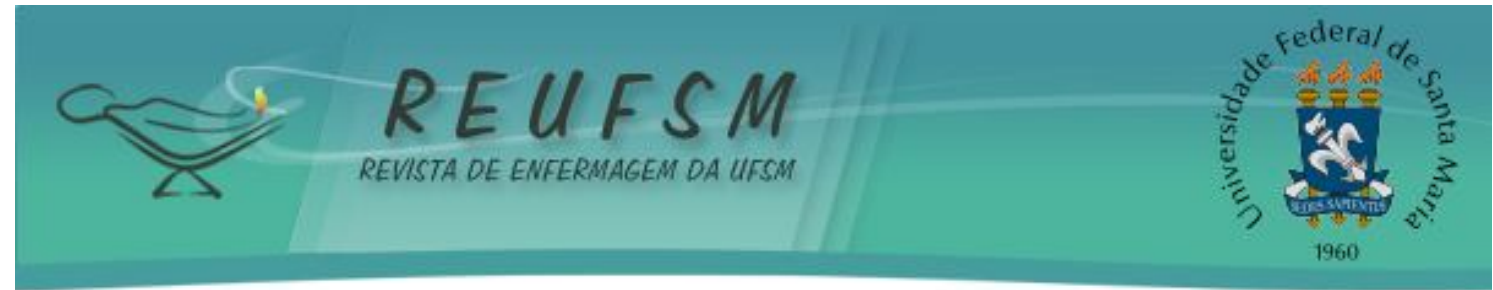

18. Landerdahl MC. Programa de Extensão "Mulheres Conquistando Cidadania"-MEC/ SESu. Santa Maria: [s.n.] 2009. 50p. Projeto de Extensão- Universidade Federal de Santa Maria. Centro de Ciências da Saúde - Departamento de Enfermagem; 2009.

19. Bordenave J D. Estratégia de ensino-aprendizagem. Petrópolis (RJ ): Vozes; 1989.

20. Landerdahl MC. Curso de Aperfeiçoamento Gestão de Políticas Públicas em Gênero e Raça. Santa Maria: [s.n.] 2010. Projeto de Curso de Aperfeiçoamento - Universidade Federal de Santa Maria. Coordenadoria de Educação à Distância; 2010.

Data de recebimento: $30 / 09 / 2010$

Data de aceite: 20/12/2011

Contato com autora responsável: Maria Celeste Landerdahl

E-mail: mclanderdahl@gmail.com 